\title{
Risk Prediction and Dynamic Risk Simulation of Each Stage of E-government System Outsourcing*
}

\author{
Youshi $\mathrm{He}^{1, \text { a }}$, Yu Lu ${ }^{1, b}$ \\ ${ }^{1}$ School of Management, Jiangsu University, 212013 Zhenjiang, Jiangsu Province, PR China \\ aheyshi@ujs.edu.cn, bluyu0421@126.com
}

Keywords: e-government system, outsourcing, risk prediction, dynamic simulation

\begin{abstract}
The purpose of this paper is to analyze basic theory of E-government system outsourcing and risk management theory, identify 33 risk factors of four stage of E-governmnt system outsourcing under asymmetric information, determine weights of all kinds of risks and the risk factors through empirical research and statistical analysis, build E-government system outsourcing risk system dynamics model, show a cause-and-effect relationship and function mechanism between risk factors. Through simulation the paper finds out the development trend of outsourcing decision-making risk, outsourcer selection risk, system construction risk, system operational risk, overall risk of outsourcing, and outsourcing performance, and more accurately reflect main risks and control strategy. The simulation found that the risk of outsourcing decision stage and contract execution stage are the two main factors of influencing e-government system outsourcing. And specific strategies for controlling the risk of each stage are found out.
\end{abstract}

\section{Introduction}

At present, governments have seen the electronic government system outsourcing (EGSO) as an efficient way to realize government information and improve the efficiency of government services. The emphasis of scholars' research on the risk of e-government system outsourcing (or outsourcing) were different. Scholars mainly combined with the actual case to analysis risk factor identification, causes and corresponding control strategies in outsourcing process. France Belanger and Lemuria Carter analyzed trusts and risks (people, technology, communication, supervision and other risks) in e-government when using it.

They confirmed the cause-and-effect relationship between the trust and risk factors combined with empirical survey data[1]. Jane Fedorowicz etc. pointed out that there were multiple risks in implementing the e-government, such as the contract management risk, moral risk, privacy risk and cost risk. They used empirical analysis to research motivation of participants in e-government outsourcing implementation, and predict a more balanced strategy that the parties will take [2]. Lascano, etc. pointed out that outsourcing risk mainly came from agents, principals and outsourcing transaction processes in the study of IT outsourcing risk factors [3]. Chao-Che Hsu etc, propose a new hybrid Multiple Criteria Decision-Making (MCDM) model, which combines the decision making trial and evaluation laboratory and the analytical network process method[4]. Chitrasen Samantra etc. explore a hierarchical IT Outsourcing risk structure representation to develop a formal model for qualitative risk assessment[5]. Tobias Schoenherr etc. hypothesize about antecedents to trust formation in buyer-supplier relationships; specifically, they consider the exchange relationship aspects of process integration, contract flexibility and cultural understanding[6]. Frank Martin Rennung etc. develop an evaluation model to assess potential complexity-related risks in the context of strategic project outsourcing[7]. Sikandar Ali and Siffat Ullah Khan develop a software outsourcing partnership model to identify and analyze factors [8] .

A great deal of literatures on outsourcing risks appears at present in this field, but few can be seen on e-government system outsourcing risks. This paper used system dynamics method to study formation theory and relationship of E-government systems outsourcing risks, used computer simulation to predict running states and developing trends of risk subsystems, indicated the main 
risks affecting e-government systems outsourcing, and found out control measures for each risk subsystem.

\section{Building system dynamics model of EGSO risk}

\subsection{Overall structure of EGSO risk}

E-government systems outsourcing risks system has dynamic nature, complexity and multiple feedbacks, and corresponds to the characteristics of the influence on system behavior such as structure relations and temporal information. According to the theory of decision-making process, EGSO is divided into four stages: outsourcing decision-making stage, contract signing stage, contract execution stage, and result evaluation stage.

Among them, the work of outsourcing decision-making stage mainly includes: deciding whether outsourcing related business, ensuring the scope and mode of outsourcing, selecting contractors etc. At this stage, the government departments need to evaluate internal so as to differentiate core business, and ensure outsourcing target; they also need to evaluate contractors so as to determine the cooperative contractor. After choosing the contractor, the government and the contractor begin to cooperate in the form of a contract. Therefore, the formation, setting and signing of the contract are very important. The work of contract signing stage mainly includes: negotiating the agreement period, outsourcing service contents, rights and obligations in both parties, solution of disputes, etc. The contract execution stage involves the concrete implementation of outsourcing activities, internal coordination and supervision, managing relationships with the contractor, controlling of outsourcing schedule, risk prevention, etc. The work of result evaluation stage includes reviewing and assessing the completion of each result, and the government evaluates the quality and service level of the e-government system that provided by the contractor.

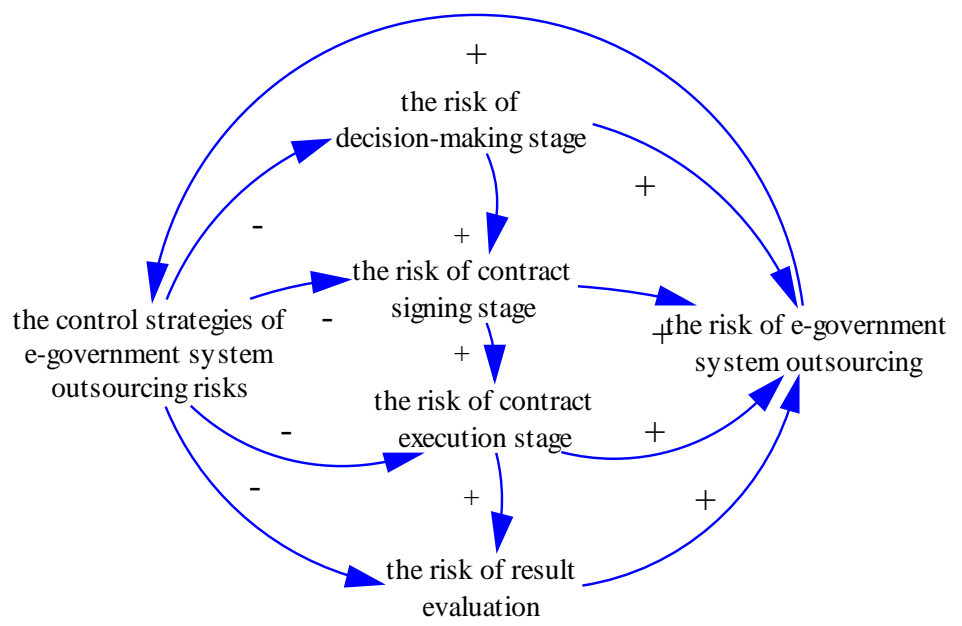

Figure 1. The overall structure of the EGSO risk system

According to the decision process of EGSO, the risk system structure of e-government system outsourcing can be divided into four subsystems: the risk subsystem of outsourcing decision-making stage, the risk subsystem of contract-signing stage, the risk subsystem of contract execution stage, the risk subsystem of results evaluation stage, as shown in Figure 1. In Figure 1, the EGSO risk system is a feedback system, and the specific feedback loop is from each stage's risks, e-government system outsourcing risk and control strategies of EGSO risks. The outsourcing performance and the gap between the outsourcing performance and expected goal are included in the system. The EGSO risk increases, the performance is reduced, and the gap is increased. So the outsourcing risk can reflect the gap between outsourcing performance and expected goal. The risk factors in the system are interacting. When the risk of each stage of the EGSO increases, the total EGSO risk increases. It prompts to strengthen controlling strategies so as to reduce risks and improve outsourcing performance. So the cycle continues, until the system is in a steady state. 


\subsection{Risk factors analysis of EGSO}

The EGSO activities consist of the government department and the contractor. Because of the principal-agent relationship between the two parties, there is information asymmetry in them that makes the government department be face with outsourcing risks such as losing the capacity of information technology, the contractor hides information, the service level of e-government system is not standard, etc. At the same time, the EGSO is affected by external environment factors such as policies and laws, economic and social factors. Based on the four stages of EGSO, this paper divided the risks into 9 levels: environment risk of outsourcing industry, risk of strategic decision, human resources risk of government, risk of contract management, risk of process management, technology risk, process risk, quality risk of system and system acceptance risk. Each level contains a number of risk factors. Through analyzing and researching actual cases at home and abroad, this paper selected 33 risk factors to conduct a questionnaire survey. Respondents are experts and scholars who research on information system outsourcing, and staffs working in government information departments in Shandong, Jiangsu and Zhejiang province. 361 questionnaires are sent out. 247 questionnaires are taken back. 213 questionnaires are valid. According to the collected data, risk factors analysis is taken. Three factors are eliminated. They respectively are "difficult development technology", "poor of team behavior", and "poor of government monitoring”. A total of 30 factors with significance of statistics and management are extracted. Cause trees of each risk subsystem are shown in Table 1.

[Table 1. Cause of EGSO risk factors]

\begin{tabular}{|c|c|c|}
\hline $\begin{array}{l}\text { risk of } \\
\text { outsourcing stage }\end{array}$ & risk classification & affecting factors \\
\hline \multirow{3}{*}{$\begin{array}{l}\text { risk of } \\
\text { decision-making } \\
\text { stage }\end{array}$} & $\begin{array}{c}\text { human resources risk } \\
\text { of government }\end{array}$ & $\begin{array}{l}\text { declining IT level; lack of outsourcing knowledge } \\
\text { lack of the remaining IT capacity; lose responsibility }\end{array}$ \\
\hline & $\begin{array}{l}\text { outsourcing industry } \\
\text { environment risk }\end{array}$ & $\begin{array}{l}\text { economic and social factors; few contractors } \\
\text { immature outsourcing market } \\
\text { imperfect lows and regulations }\end{array}$ \\
\hline & $\begin{array}{l}\text { strategic decision } \\
\text { risk }\end{array}$ & $\begin{array}{l}\text { adverse selection; decision failure } \\
\text { improper outsourcing scope } \\
\text { inaccurate evaluation to contractors }\end{array}$ \\
\hline $\begin{array}{l}\text { risk of contract } \\
\text { signing stage }\end{array}$ & $\begin{array}{l}\text { contract } \\
\text { management risk }\end{array}$ & $\begin{array}{l}\text { incomplete contract; inflexible contract } \\
\text { specificity; the contractor hides information }\end{array}$ \\
\hline \multirow[t]{3}{*}{$\begin{array}{l}\text { risk of contract } \\
\text { execution stage }\end{array}$} & $\begin{array}{l}\text { process management } \\
\text { risk }\end{array}$ & $\begin{array}{l}\text { defects of menbers structure of the contractor } \\
\text { inaccurate demand analysis from the contractor } \\
\text { lack of communication } \\
\text { lack of supports from government } \\
\text { the government constantly changes requirements } \\
\text { the government lack of monitoring }\end{array}$ \\
\hline & schedule risk & $\begin{array}{l}\text { delay of the plan } \\
\text { the development system cannot meet request }\end{array}$ \\
\hline & technology risk & $\begin{array}{l}\text { the contractor lacks ITcapacity } \\
\text { the uncertainty of technology update }\end{array}$ \\
\hline \multirow{2}{*}{$\begin{array}{l}\text { risk of result } \\
\text { evaluation stage }\end{array}$} & $\begin{array}{l}\text { acceptance check } \\
\text { risk of system }\end{array}$ & $\begin{array}{l}\text { lack of effective indicators of performance evaluation } \\
\text { unrealistic expectation from the government }\end{array}$ \\
\hline & $\begin{array}{l}\text { quality risk } \\
\text { of system }\end{array}$ & $\begin{array}{l}\text { lack of system maintenance technology } \\
\text { service level of system is not standard }\end{array}$ \\
\hline
\end{tabular}




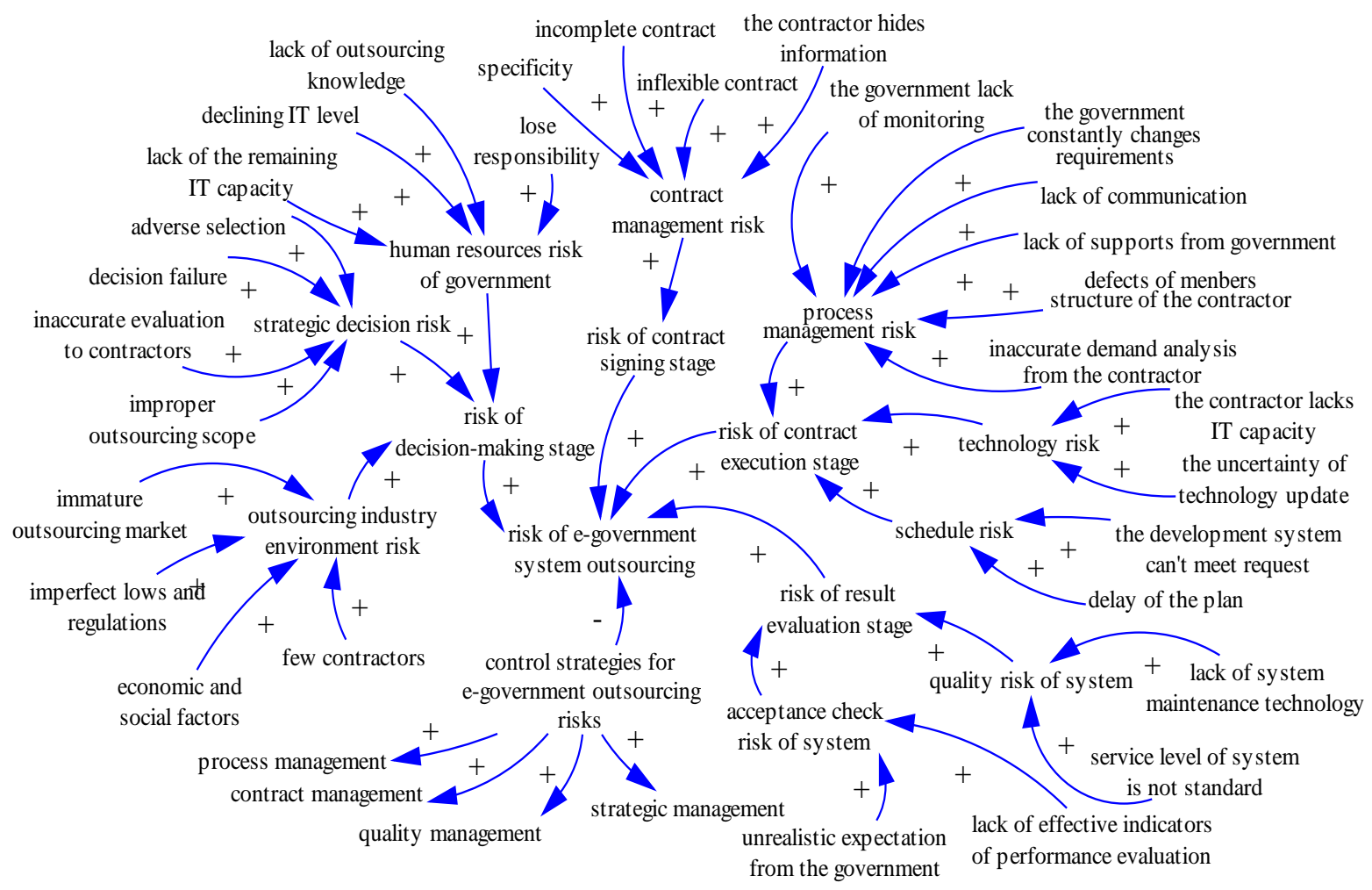

Figure 2. Causality of EGSO risk

On the basis of cause trees, further research on the dynamic relationship among risk factors of each subsystem can be shown in Figure 3. Management of EGSO risk mainly done through control strategy. Control strategies of the EGSO risks mainly include strategic management, contract management, process management, and quality management. The strategic management runs through the first three stages of EGSO. It is used to guarantee implementing strategic plan. From signing contract to terminating contract, the contract management is applied to reduce risks caused by incomplete and inflexible contract. The process management and the quality management mainly control the risks of contract execution stage and result evaluation stage.

\subsection{The system dynamics model of EGSO risk}

On the basis of qualitative description of the causality diagram, a flow diagram is drawn to carry on a quantitative research. This paper sets the four stage risks as state variables, and selects the incidence of risks and control rate of risks as speed variables. The system flow diagram is shown in Figure 4.

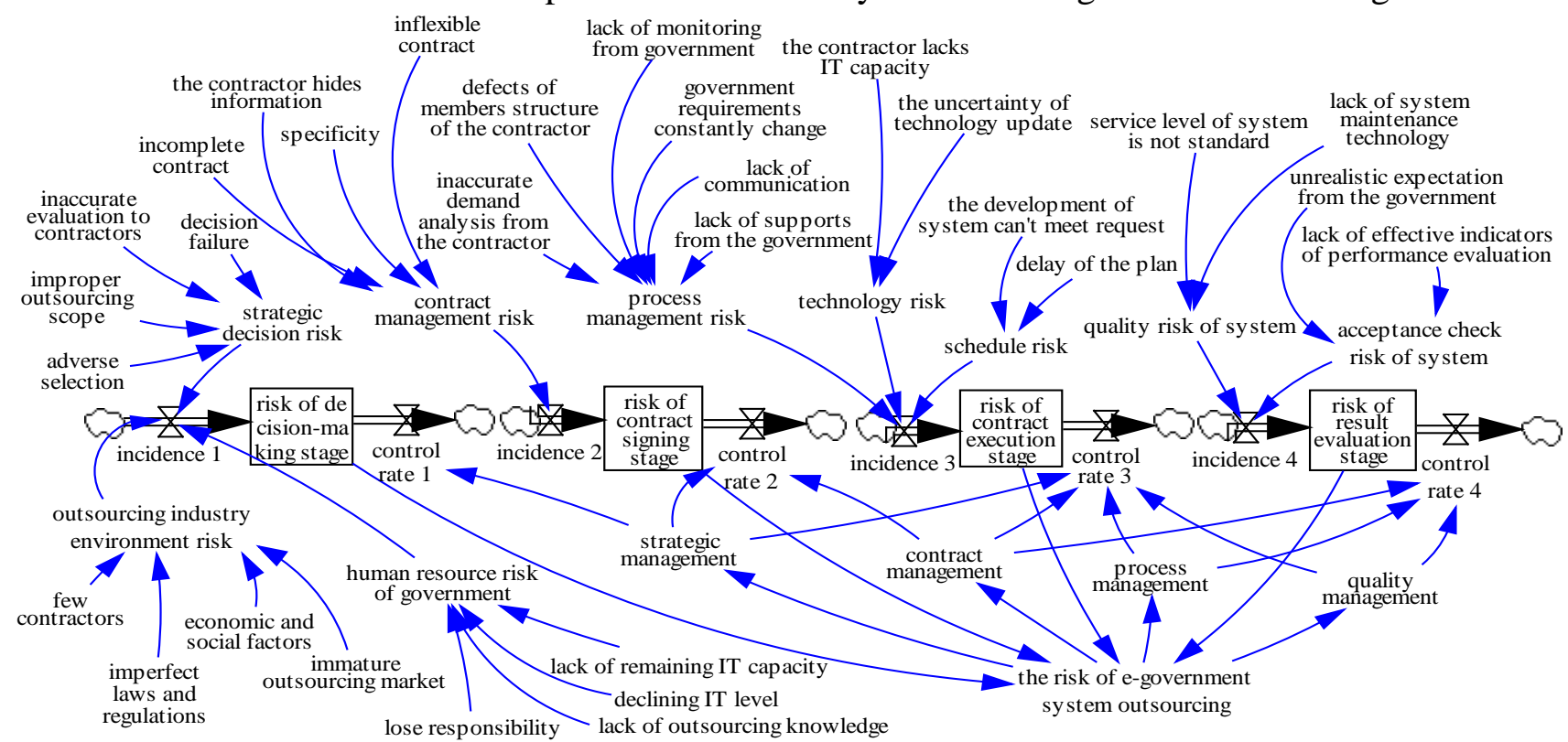

Figure3. The flow diagram of risk system in EGSO 
By using the Delphi method, the main persons-in-charge working in surveyed company as well as the experts in this field are consulted, and then each risk factors of EGSO are scored by them, finally determine the weights of all risk factors to incidence of EGSO risk . In accordance with this the dynamic equations are constructed, as is shown in Table 2.

[Table 2. The main dynamic equations in EGSO risk system]

\begin{tabular}{|c|c|c|c|}
\hline $\begin{array}{c}\text { Rate } \\
\text { variable }\end{array}$ & Dynamic equation & $\begin{array}{c}\text { Rate } \\
\text { variable }\end{array}$ & Dynamic equation \\
\hline incidence 1 & $\begin{array}{l}=3 * \text { outsourcing industry } \\
\text { environment } \\
\text { risk } / 10+4 * \text { strategic decision } \\
\text { risk } / 10+3 * \text { human resource } \\
\text { risk of government } / 10\end{array}$ & $\begin{array}{c}\text { control rate } \\
1\end{array}$ & $\begin{array}{l}=\text { DELAY3(strategic } \\
\text { management,2) }\end{array}$ \\
\hline incidence 2 & $=$ contract management risk & $\begin{array}{c}\text { control rate } \\
2\end{array}$ & $\begin{array}{l}=\quad \text { DELAY3((contract } \\
\text { management+strategic } \\
\text { management }) / 2,2)\end{array}$ \\
\hline incidence 3 & $\begin{array}{l}=\quad 6 * \text { technology } \\
\text { risk } / 16+5 * \text { process } \\
\text { management } \\
\text { risk } / 16+5 * \text { schedule risk } / 16\end{array}$ & $\begin{array}{c}\text { control rate } \\
3\end{array}$ & $\begin{array}{l}=\text { DELAY3 }((\text { strategic } \\
\text { management }+ \text { contract } \\
\text { management }+ \text { process } \\
\text { management }+ \text { quality } \\
\text { management }) / 4,2)\end{array}$ \\
\hline incidence 4 & $\begin{array}{l}=5^{*} \text { quality risk of } \\
\text { system } / 11+6^{*} \text { acceptance } \\
\text { check risk of system } / 11\end{array}$ & $\begin{array}{c}\text { control rate } \\
4\end{array}$ & $\begin{array}{l}=\text { DELAY3((contract } \\
\text { management }+ \text { process } \\
\text { management }+ \text { quality } \\
\text { management }) / 3,2)\end{array}$ \\
\hline $\begin{array}{l}\text { Box variable } \\
\text { The risk of } \\
\text { stage }\end{array}$ & each Dynamic & uation & $\therefore$ \\
\hline
\end{tabular}

\section{Simulation of EGSO risk system dynamics model}

\subsection{Parameter settings}

The simulation time is 8 years. In month, it's a total of 96 months. The influence degree of all kinds of risks to the incidence is determined by the expert investigation method. The initial value of risk factors is between $0 \sim 0.1$, and the initial value is relative amount, it has not substantial effect on the simulation results. With the increase of e-government system outsourcing risk, the strategic management, process management, quality management $=(0,0.4,0.45,0.5,0.55,0.6,0.7,0.8,0.9$, 0.99), the contract management $=$ IF THEN ELSE $($ EGSO risk $<=0.11,0.15$, IF THEN ELSE (EGSO risk $<=0.31,0.69,0.99)$ ).

\subsection{Analysis of simulation results}

By using Vensim PLE software to simulate the dynamic model, the simulation results of the four stages are shown in Figure 6. In Figure 6, both the risks of the decision-making stage and the result evaluation stage show a downward trend after rising first. The risk of decision-making stage is relative high in 4-40 months, and declines slowly after the 40th month. The risk of result evaluation stage rises in 1-9 months, and then presents downward trend after the 9th month. Both the risks of contract signing stage and contract execution stage are on the rise, and the risk of contract signing stage shows a more obvious increase. The risk of contract execution stage appears four times large fluctuations, increased in a fluctuant way, and then levels off after the 40th month. 


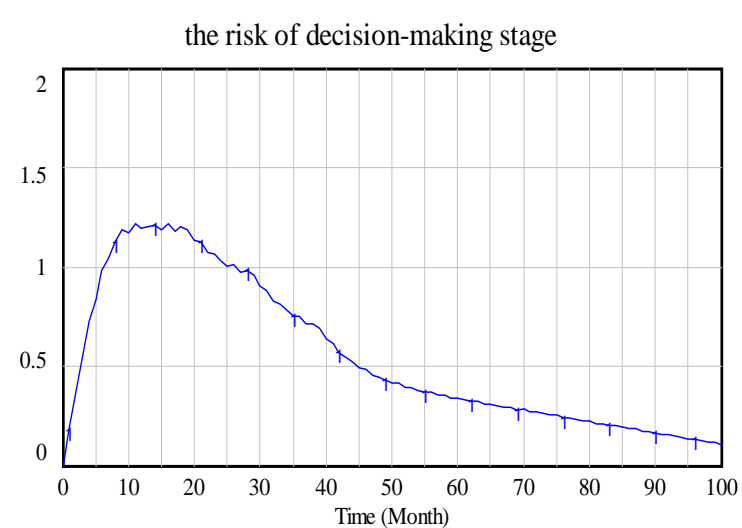

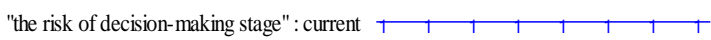

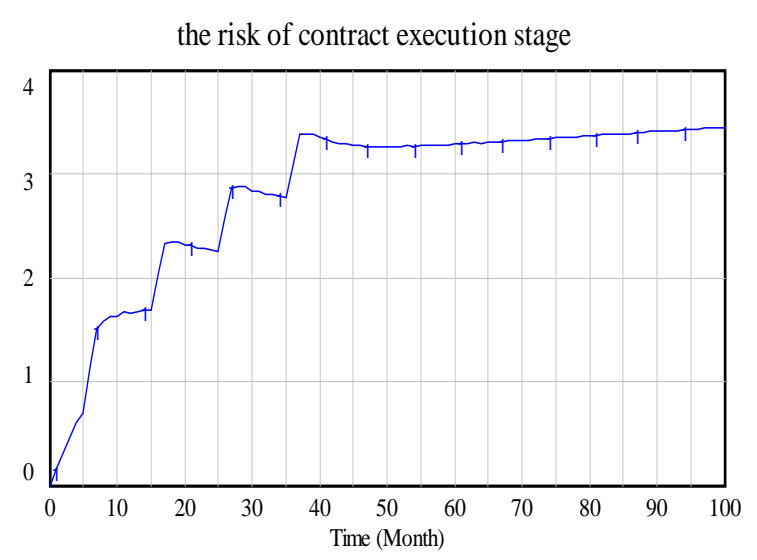

the risk of contract execution stage : current

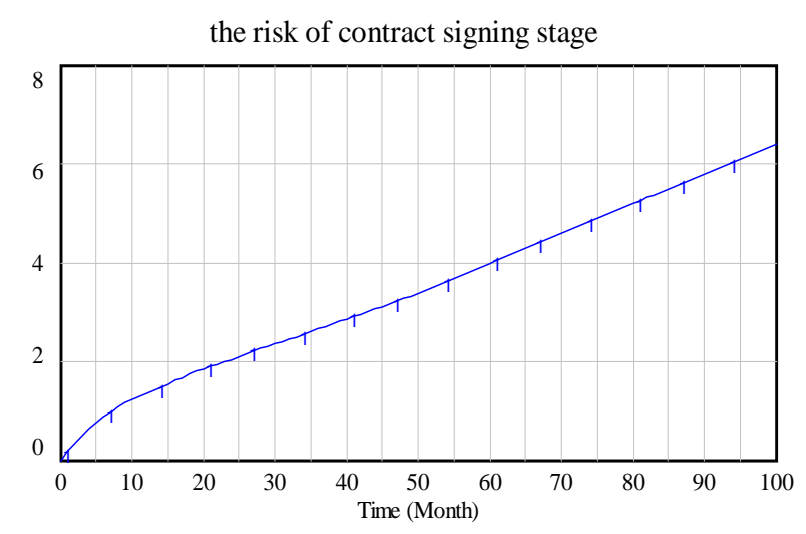

the risk of contract signing stage : current

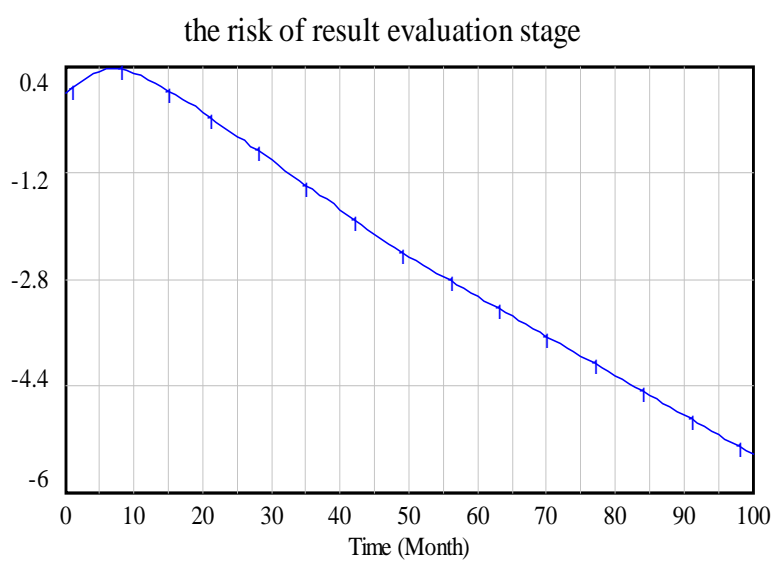

the risk of result evaluation stage : current $\begin{array}{llllll}1 & 1 & 1 & 1 & 1 & 1\end{array}$

Figure 4. The development trend of risks in different stages

By the above analysis of trend-forecast, we can know that the risks of the contract signing stage and the contract execution stage are the main risks of EGSO. In contract execution stage, fluctuating increase is shown due to the presence of the management risk, the technology risk and the process risk in the contract execution stage. This suggests that the trend of risk appears repetition in the risk control. Because the government departments continue disclosing information to the contractor in the contract period, the government's management capacity declines and risk control strength is insufficient. It causes the risk of contract signing stage increased. In addition, a certain time delay exists in the risk control process that makes the risks of the decision-making stage and the result evaluation stage appear to rise and then fall.

\section{Risk control of the EGSO}

According to the simulation results of the risk system model of EGSO, both the risks of the contract signing stage and the contract execution stage are the key risks of EGSO. Although both the risks of the outsourcing decision-making stage and the result evaluation stage ultimately show a downward trend, the risks appear a more high-level upward trend in the early period. Therefore, the government needs to strengthen risk management including the strategic management, contract management, process management and quality management to control risk at a low level so that the performance of EGSO can be improved. Then, each risk control measure is increased by 0.2 of respectively on the basis of the initial value and the other three remain unchanged, so we will get the relative influence to EGSO of the four risk control measures. As shown in Figure 6. 

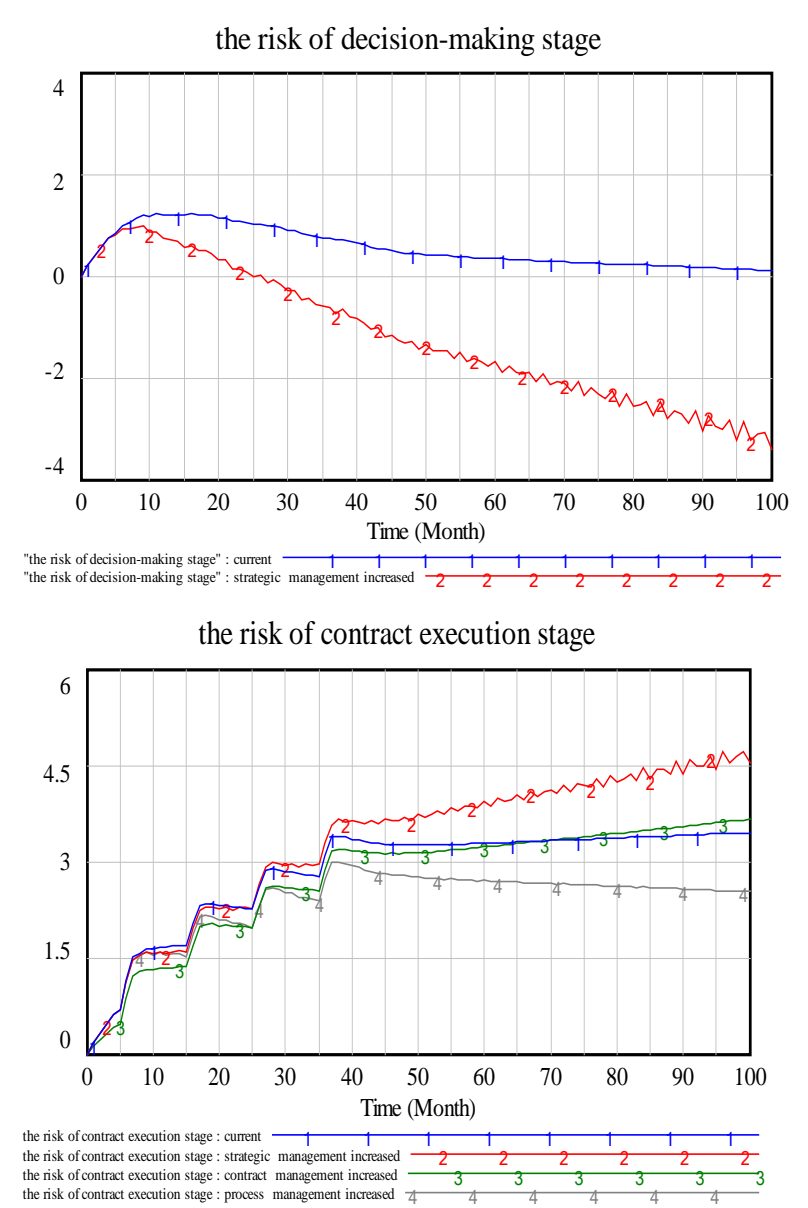
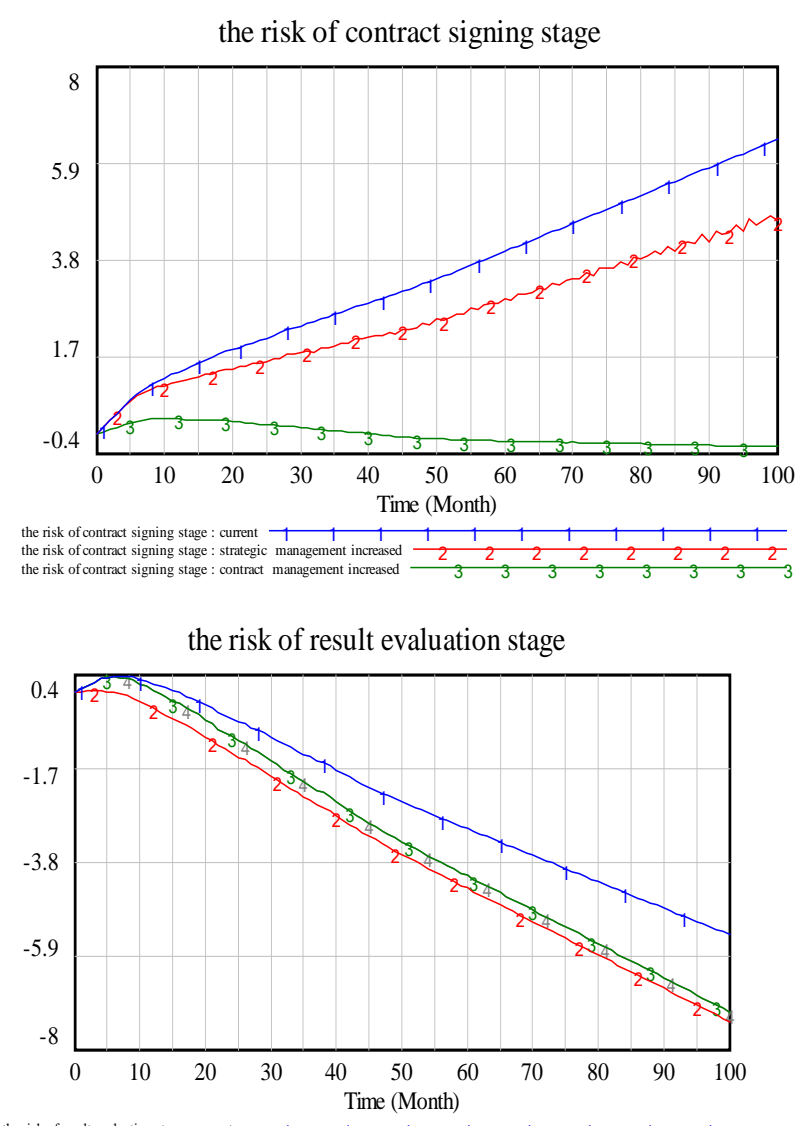

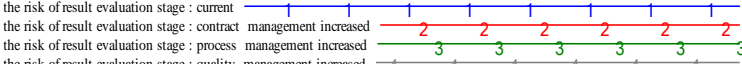

Figure 5. The relative risk influence by adjusting control strategies

At the outsourcing decision-making stage, the risk control mainly depends on strategic management. In Figure 6 , if the strategic management increases by 0.2 , namely the strategic management $=(0,0.6,0.65,0.7$, $0.75,0.8,0.9,0.99,0.99,0.99)$, the risk of this stage decreases significantly. So the government department should do scientific planning, make precise judgment and give cautious prediction when drawing up outsourcing strategies. The standards of the strategic decision directly affect the EGSO risk.

At the contract signing stage, the risk control mainly relies on strategic management and contract management. If the strategic management and contract management separately increased by 0.2 , the influence degree: Contract Management> Strategic Management.

At the contract execution stage, the influence degree of the four risk control measures: process management $=$ quality management $>$ contract management $>$ strategic management. What needs to be noticed is that the risk of contract execution stage is larger than the initial value when enhancing strategy management. This illustrates it is not wise to increase the strategic management at the contract execution stage. The reason is that the key point of strategic management is setting an overall and long term plan, strategic target, task and policy, and then properly allocating resources in the prophase of EGSO, and finally putting such strategies to practice in metaphase and anaphase. If enhancing the strategic management in this stage, there will be tremendous impact to the ongoing plans and the government cost will be increased, which makes the risk increase eventually. In Figure 6, strengthening the process management and the quality management can reduce the risk of contract execution, but it is not needed to increase strategic management and contract management.

When the contract management, the process management and the quality management separately increase by 0.2 , the impact to the risk of result evaluation stage is that: contract management $>$ process management $=$ quality management. At the result evolution stage, the contract will be end, and increasing the contract management can reduce the risks like the system service doesn't meet contract demands, lack of contractor's maintaining technology and the contract disputation. Therefore, the 
benefit of increasing the contract management is larger than the process management or the quality management.

\section{Conclusions}

A dynamic model of EGSO risk system is built and simulated based on system dynamics in this paper. According to simulation results, the paper concludes as follows:

1. The risk trends of the outsourcing decision-making stage and the result evaluation stage increase first and then decrease in the simulation range. The risk trends of the contract signing stage and the contract execution stage is on the rise. And the risk of contract execution stage increases with fluctuations, and tends to level off after 40 months.

2. The risks of the contract signing stage and the contract executing stage are the main risks of the EGSO. They play important roles in the overall risk of the EGSO, so more focus should be put on reducing the risks of these two stages. Due to time delay, a higher level risk exists in the simulation prophase of decision-making stage and result evaluation stage.

3. Strengthening strategic management can reduce the risk of outsourcing decision-making stage effectively; at the contract signing stage, the result of strengthening the contract management is more conspicuous than strengthening the strategic management; strengthening the process management and the quality management can reduce the risk of contract execution stage, and there is no need to strengthen strategic management and contract management; at result evaluation stage, strengthening the contract management is needed to reduce the risk, and the result of strengthening the contract management is better than strengthening the process management or the quality management.

\section{Acknowledgments}

This work was supported by the National social Science Foundation of China (10BGL097), MOE (Ministry of Education in China) Project of Humanities and Social Sciences youth Foundation(11YJC630234). Sponsorship project: the National social Science Foundation of China (16BGL088)

\section{References}

[1] France Belanger, Lemuria Carter, Trust and Risk in E-government Adoption, The Journal of Strategic Information Systems, vol. 17, no. 2, (2008), pp. 165-176.

[2] Jane Fedorowicz, Ulric J. Gelinas Jr., Janis L. Gogan, Christine B. Williams, Strategic Alignment of Participant Motivations in E-government Collaborations: The Internet Payment Platform Pilot, Government Information Quarterly, vol. 26, no. 1, (2009), pp. 51-59.

[3] Lascano N, Maniasi S, Colla P, A Structured Framework for Managing Offshore Outsourcing Risks on Software Support Projects, Saint Petersburg, Russia: Software Engineering Approaches for offshore and Outsourced Development, (2010), pp. 87-95.

[4] Chao-Che Hsu, James J.H. Liou, An outsourcing provider decision model for the airline industry,Journal of Air Transport Management, Vol. 28, no.3,(2013), pp.40-46

[5] Chitrasen Samantra, Saurav Datta, Siba Shankar Mahapatra,Risk assessment in IT outsourcing using fuzzy decision-making approach: An Indian perspective,Expert Systems with Applications, Vol. 41, Issue 8, 15 no.6,(2014), pp. 4010-4022

[6] Tobias Schoenherr, Sriram Narayanan, Ram Narasimhan,Trust formation in outsourcing relationships: A social exchange theoretic perspective, International Journal of Production Economics, Vol. 169, no.11,(2015), pp. 401-412

[7] Frank Martin Rennung, Caius Tudor Luminosu, Anca Draghici,Strategic Management - Managing The Potential Complexity-risks In Outsourcing,Procedia Economics and Finance, Vol.26, (2015), pp.757-763 
[8] Sikandar Ali, Siffat Ullah Kha, Software outsourcing partnership model: An evaluation framework for vendor organizations,Journal of Systems and Software, Vol. 117,no.7,(2016), pp. 402-425 